\title{
Reseña: Alba Carosio (coord.) "Feminismo y cambio social en América Latina y el Caribe". CLACSO. 272 páginas. 2012.
}

\author{
Joaquín Bartlett ${ }^{*}$
}

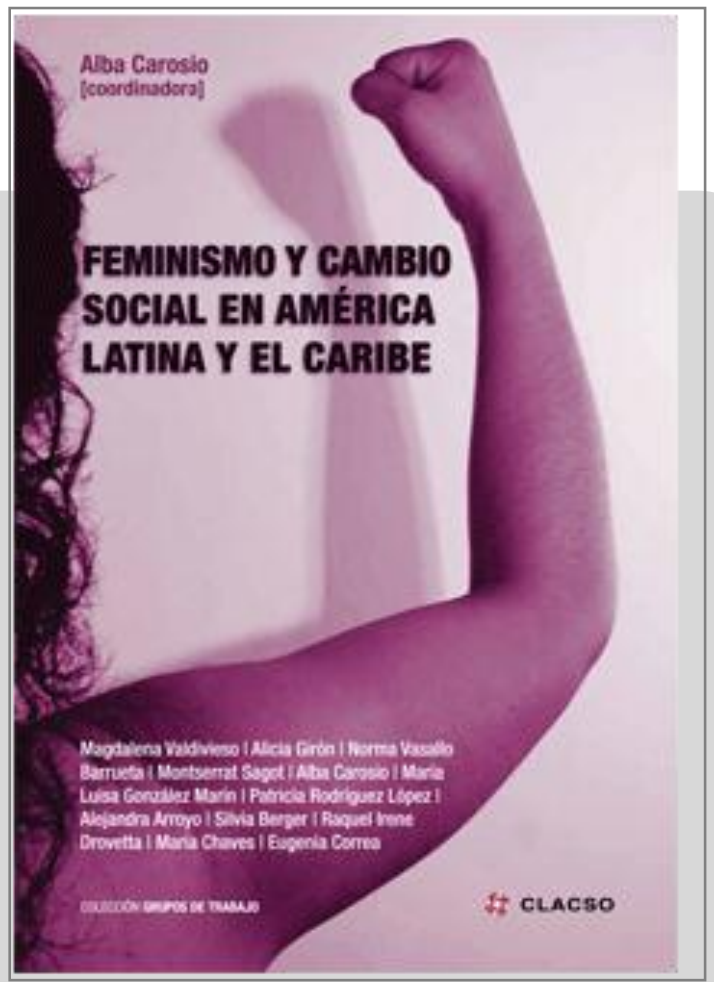

Disponible en:

http://bibliotecavirtual.clacso.org.ar/clacso/gt/20120912031117/Feminismoycambiosocial.pdf

La primera certeza que surge, por más que parezca obvia, del libro coordinado por Alba Carosio es que no se pueden pensar los procesos emancipatorios en América Latina sin los aportes y experiencias de los feminismos. El amplio camino recorrido por

* Licenciado en Relaciones Laborales - Universidad Nacional del Nordeste - Argentina. 
las activistas feministas pone en evidencia que la construcción de una teoría crítica no se puede desapegar la praxis política. En ese sentido caminan los trabajos reunidos en la publicación que surge de la 1. ${ }^{a}$ Reunión del Grupo de Trabajo Feminismo y Cambio en América Latina y el Caribe, realizada en Caracas a mediados de 2011. En esencia no se trata de una publicación con temática de género; en ese punto se diferencia al dejar explícito que feminismo y género no son términos intercambiables de manera acrítica y que este último no abarca al primero al ser una parte de él.

La publicación consta de once artículos que se pueden hilvanar en función de diferentes aspectos y modos de visualizar los marcos de opresión en contextos específicos: mercado de trabajo, salud, políticas sociales, migración. También brinda un panorama, que sin perder profundidad, introduce a los debates actuales de los feminismos. El amplio abanico de temáticas abordadas plantea los importantes avances en materia de análisis feminista, a la vez que da cuenta de los aportes académicos en la práctica política de los feminismos.

Los aportes se inician con el trabajo de Magdalena Valdivieso ${ }^{1}$, en el cual reflexiona sobre los debates en torno a la ciudadanía y la democracia, reconociendo las contribuciones de los feminismos. Para ello da cuenta de las diversas formas de organización de las mujeres y cómo han incidido en las estructuras para la definición de los "asuntos públicos". Tomando como ejemplos los procesos de Bolivia, Ecuador y Venezuela, la autora analiza los modos de institucionalización enmarcados en las reformas constitucionales, de las reivindicaciones y demandas de los movimientos de mujeres, como así también su articulación con otros colectivos y en especial los pueblos originarios. Por otra parte, dichos procesos implican para la autora pensar un feminismo latinoamericano no jerarquizado que no niega los aportes europeos, pero que a su vez, "en el ámbito del conocimiento, de los saberes, de la memoria, dentro de la reflexión y práctica de las luchas por la emancipación" se pose desde una perspectiva no colonial.

Alicia Girón ${ }^{2}$, por su parte, se pregunta ¿cómo se puede articular, desde una visión de género, el impacto que han tenido las crisis económicas recurrentes y la crisis económica en curso en un terreno de fragilidad financiera constante? Para la autora el acceso al mercado laboral de las mujeres, "más que una emancipación" fue el modo en que el capital pudo crecer en rentabilidad a la vez que disminuir los salarios. La vinculación de la que parte se centra en la relación feminismo-neoliberalismo y la inserción de las mujeres en el mercado laboral como punto de convergencia. La autora recorre el mercado laboral latinoamericano para poner en relieve cómo se han transformado, mediante sucesivas crisis económicas y financieras, las pautas de las

\footnotetext{
1 "Aportes e incidencia de los feminismos en el debate sobre ciudadanía y democracia en América Latina" (pp. 19 - 42).

2 "Feminismo. Quiebres y zurcidos en crisis" (pp. $43-56$ ).
} 
mujeres como generadoras de ingresos y principal pilar en la reproducción y cuidado de la fuerza de trabajo.

El artículo de Norma Vasallo ${ }^{3}$ presenta una exploración y recorrido por las profundas transformaciones impulsadas por el Proyecto Social de la Revolución Cubana y en qué medida dichos cambios fueron acompañados por la construcción colectiva de una subjetividad femenina en un contexto patriarcal. Para la autora se hace necesario mantener espacios ganados de participación política que involucren también a los hombres en las transformaciones, desde un plano subjetivo, que acompañan a la Revolución Cubana.

La participación política de feministas centroamericanas se ve expuesta en el trabajo de Montserrat Sagot ${ }^{4}$, que presenta la agenda feminista en su región atravesada y en tensión con la necesidad de ganar y mantener espacios institucionalizados, con el riesgo de ser asimilados o construir autonomía manteniendo una postura radical. A partir de sus análisis, Montserrat Sogot destaca los avances en materia normativa, pero a la vez describe los diferentes escollos en la implementación de políticas públicas en materia de género, aspectos que ponen discusión la relación movimiento feminista y Estado. La autora describe su región desde tres aspectos: neoliberalismo, fascismo social y neointegrismo, elementos que asumen ciertas particularidades en la región que lleva a la agenda feminista a una continua rediscusión de los aspectos centrales por donde avanzar.

Venezuela vuelve a surgir, de manera específica, para el trabajo presentado por Alba Carosio $^{5}$, en el que pone de relieve el protagonismo de las mujeres en el proceso bolivariano. Tomando la nueva Constitución, se describen los puntos de influencia en políticas contra la pobreza, el caso particular de las Misiones y la legislación de género. El énfasis está puesto en la nueva construcción del poder popular y el surgimiento de las mujeres como sujetas políticas antes circunscritas a roles normalizados de género. Carosio plantea de manera clara que el componente de lo popular en la relación feminismo y política tiñe y revitaliza al movimiento, en tanto que implica espacios valiosos de participación, como por ejemplo el caso de las Misiones, Comités de Tierra Urbana y Concejos Comunales.

María Luisa González Marín y Patricia Rodríguez López ${ }^{6}$ abordan la temática de la migración de las mujeres hispanas hacia EE. UU. según datos socioeconómicos. En búsqueda de los impactos que acarrea la crisis en la realidad de las migrantes de origen centroamericano, se visualizan las transformaciones en aspectos relacionados con la pobreza, seguridad social, salarios y ocupaciones.

\footnotetext{
3 "Subjetividad femenina y cambio social en Cuba" (pp. 57 - 74).

4 "¿Un paso adelante y dos atrás? La tortuosa marcha del movimiento feminista en la era del neointegrismo y del 'fascismo social' en Centroamérica" (pp. 75 - 100).

5 "Mujeres hacia el socialismo feminista en Venezuela" (pp. 101 - 136).

6 "La crisis económica y el mercado de trabajo de las migrantes hispanas en Estados Unidos de América" (pp. 137 - 160).
} 
Por su parte, Alejandra Arroyo $^{7}$ también aborda la migración desde el caso de las mujeres residentes en España. Se parte de los lazos culturales que posibilitaron a las migrantes de América Latina proveer mano de obra calificada y no calificada. El foco de atención está dado en las políticas migratorias y una rigurosa descripción de los aspectos que desbocaron en la crisis económica de España.

Para el caso de Argentina, Silvia Berger $^{8}$ se remonta a fines del siglo XIX para caracterizar y analizar, con un importante apoyo estadístico, las bases de construcción de la familia nuclear. Con la meta de generar una historia comparada de los países de América Latina en materia de desigualdad de género, el texto de Silvia Berger no solo marca la participación de las mujeres en el mercado de trabajo, sino también los elementos que conllevan la reproducción social que prima en el ámbito doméstico. Los tres momentos de acumulación descritos por la autora (oligárquica, de sustitución de importaciones y de predominio del capital financiero), aunque diferentes, contribuyen a modo de "guía histórica" como elementos que en materia de género presentan y asumen regularidades y continuidades para tener presentes.

El trabajo de Raquel Irene Drovetta ${ }^{9}$ presenta un análisis de las trayectorias reproductivas femeninas de las mujeres de la etnia atacama en Susques, provincia de Jujuy. Partiendo de dos generaciones y de manera comparativa, la autora toma indicadores conformados por acontecimientos (embarazo, parto y el puerperio) en los que confluyen construcciones diversas; por ejemplo, sobre la interacción con los agentes de salud. Sumada a lo anterior, la descripción detalla el sistema sanitario de Susques, y le permite visualizar las acciones de la institución biomédica que llevan a la modificación de las trayectorias reproductivas femeninas.

Una de las luchas más significativas de los feminismos, la decisión sobre el cuerpo, es abordada por María Chaves $^{10}$ en su recorrido por la participación política de colectivos de mujeres que pusieron en escena el derecho al aborto en la Argentina pos2001. La autora traza, desde los levantamientos de 2001 hasta la actualidad, los hechos significativos que permitieron vigorizar e impulsar las discusiones en torno a la construcción de autonomía corporal del género femenino, como así también las dificultades y barreras encontradas dentro y fuera del movimiento feminista.

El libro finaliza con un análisis y propuestas de Eugenia Correa ${ }^{11}$ sobre los gastos sociales en el marco de la UNASUR. Poniendo de relieve las políticas marcadas por el consenso de Washington, el trabajo prosigue en un análisis de los gastos e ingresos

\footnotetext{
7 "Un recorrido por las políticas migratorias en España y su impacto sobre la migración femenina latinoamericana" (pp. 161 - 178).

8 "La Argentina oligárquica agroexportadora y los cambios en el orden de género" (pp. 179 - 206).

9 "Subjetividades y prácticas en salud sexual y reproductiva. Mujeres indígenas usuarias de programas estatales de salud en Argentina" (pp. 207 - 230)

10 "Derecho al aborto en Argentina. Diez años de lucha por la libertad de decidir" (pp. 231 - 251).

11 "Una perspectiva feminista sobre las políticas sociales del espacio de integración creado por UNASUR" (pp. 253 - 269).
} 
públicos de los principales países de la región. El acento puesto en el desarrollo social, desde una perspectiva de género, da cuenta de la necesidad de articulación institucional por parte de los países integrantes de la UNASUR. También enfatiza la autora posicionar a los movimientos feministas en detener las políticas de libre mercado. 